\title{
Integração e desenvolvimento econômico: estratégias de financiamento do investimento de infraestrutura sul-americana *
}

\author{
Rubia Cristina Wegner ${ }^{* *}$
}

\begin{abstract}
Resumo
O objetivo deste artigo é analisar esquemas do financiamento do investimento para integração econômica sulamericana em infraestrutura. As iniciativas consideradas abrangem aumento da participação acionária desses países no Banco de Desenvolvimento da América Latina (CAF) e sua atuação regional; Fonplata e BID. A análise destes esquemas ocorreu com base nos recursos que aportaram na carteira IIRSA-Cosiplan em relação à participação de Tesouros Nacionais pela comparação entre número e volume de recursos destinados aos EID, no escopo dos projetos que financiam, na evolução da sua carteira de créditos como um todo ou para a integração física regional e número de projetos concluídos em relação aqueles em execução e previstos naquela carteira. Um resultado que se destaca é a existência de esquemas isolados e, em parte, insuficientes de financiamento da integração física regional.
\end{abstract}

Palavras-chave: IIRSA-Cosiplan; Investimento de infraestrutura; Financiamento do investimento.

\begin{abstract}
Economic integration and development: investment financing strategies regarding south American infrastructure

The aim of this paper is to analyze the investment financing schemes for South American economic integration in infrastructure. The initiatives considered include increasing the stake of these countries in the Development Bank of Latin America (CAF) and its regional role; Fonplata and IDB. The analysis of these schemes was based on resources that included the IIRSA - Cosiplan portfolio in relation to the participation of National Treasures by comparing the number and volume of resources for the EID - the scope of the projects they finance, the evolution of its loan portfolio as a whole or for regional physical integration and number of projects completed compared to those already running and predicted for portfolio. An important result that must be highlighted is the existence of isolated schemes and, in part, inadequate regional physical integration funding.
\end{abstract}

Keywords: Integration of South America, The integration of infrastructure, Investment financing.

JEL G2.

\section{Introdução}

Em fins da década de 1990, os países sul-americanos coordenaram, sob liderança do Brasil, uma carteira comum de investimentos em infraestrutura, a Iniciativa da Infraestrutura Regional Sul-Americana (IIRSA). Havia um diagnóstico comum entre os países da região de que a inserção externa - comercial e por investimentos diretos - dependeria cada vez mais de uma visão estratégica regional sobre o ordenamento territorial sul-americano. O principal objetivo acordado pelos países sul-americanos para IIRSA foi: "impulsionar a integração e modernização da infraestrutura física sob uma concepção regional do espaço sul-americano".

\footnotetext{
*Artigo recebido em 26 de maio de 2014 e aprovado em 7 de outubro de 2017.

** Professora do Departamento de Ciências Econômicas da Universidade Federal Rural do Rio de Janeiro (UFRRJ), Seropédica, RJ, Brasil. E-mail: rubiawegner@ufrrj.br.
} 
Prevalecia, naquele momento, como destacou Padula (2010), uma visão comercialista do processo de integração regional, além das privatizações e concessões de infraestrutura notadamente no Brasil - contribuírem para uma liderança brasileira sob uma visão estritamente técnica. A elaboração e subsequente coordenação da carteira de projetos de infraestrutura foi delegada ao Comitê de Coordenação Técnica $(\mathrm{CCT})^{1}$ formado por Banco de Desenvolvimento da América Latina (CAF), Fundo Financeiro para Desenvolvimento do rio da Prata (Fonplata) e Banco Interamericano de Desenvolvimento (BID).

De 2000 a 2010, no entanto, os resultados da IIRSA foram basicamente técnicos e os mais destacáveis podem ser descritos da seguinte forma: elaboração em consenso da carteira com mais de 500 projetos em infraestrutura de transporte, energia e telecomunicações para nove eixos de integração e desenvolvimento (Eid) e elaboração de uma agenda de implementação de 31 projetos prioritários dado o forte impacto esperado para fomentar a integração AIC 2005-2010. Em 2011, a IIRSA foi incorporada pelo Conselho Sul-Americano de Infraestrutura e Planejamento da Unasul, a qual foi criada em 2008. Dessa forma, buscavase que a infraestrutura regional deveria ser articulada em torno de um acordo formal de integração - a Unasul -, com mais espaço para discussões acerca do papel do capital privado e do capital público no financiamento desses projetos.

O principal corolário institucional esperado dessa mudança era reduzir a influência das instituições financeiras na construção da infraestrutura física regional (Padula, 2014). Isto é, no âmbito da Unasul a integração regional pela infraestrutura seria executada e incrementada a partir da sua aderência a projetos de aprofundamento das relações comerciais e econômicas entre os países sul-americanos. Com o Conselho de Infraestrutura e Planejamento (Cosiplan) na gestão, a carteira de investimentos em infraestrutura se ajustaria também às ações de planejamento dos governos nacionais dos países da região. A infraestrutura passou a ser tratada como um dos elementos da integração econômica regional. Entre IIRSA e IIRSA-Cosiplan há uma diferença essencial relacionada à concepção da integração econômica regional, a qual se refletirá no desenho da carteira de projetos de infraestrutura. Essa é 'mais desenvolvimentista' (Teixeira; Desiderá Neto, 2012; Padula, 2014) e aquela 'comercialista' (Teixeira; Desiderá Neto, 2012; Padula, 2014). IIRSA teve início em um contexto no qual os países da região visavam aprofundar o alinhamento comercial com os países desenvolvidos, sobretudo os EUA. Enquanto a IIRSA-Cosiplan se inicia sob a estratégia de alinhamento comercial com os países em desenvolvimento.

Em ambos os momentos, porém, alavancar recursos para o financiamento desses projetos de investimento se tornou uma meta essencial. A exemplo da União Europeia (UE), as obras de infraestrutura têm contribuído para vincular territórios, sustentando o projeto de

(1) A estrutura organizacional da IIRSA se avalizava em mecanismos de implementação e acompanhamento do Plano de Ação e podem ser assim descritos: Comitê de Direção Executiva (CDE), Comitê de Coordenação Técnica (CCT) e Grupos Técnicos Executivos (GTEs). 
Integração e desenvolvimento econômico: estratégias de financiamento do investimento de infraestrutura...

maiores fluxos comerciais intra-regionais e de investimentos, além do trânsito de pessoas entre os países da UE. No entanto, os sistemas financeiros de países em desenvolvimento carecem de mecanismos de financiamento de investimentos desta complexidade (e.g. Mendonça, 2009; Jiménez; Manuelito, 2010, Cintra; Farhi, 2009), o que tem sido um dos fatores proeminentes para impedimento da execução e conclusão das obras de infraestrutura IIRSA-Cosiplan. Porém, passados mais de 15 anos da assinatura do acordo entre os países sul-americanos para a criação da IIRSA, essas instituições permanecem com o desafio de fazer frente à incapacidade do setor privado de financiar os investimentos em infraestrutura da integração regional.

Na literatura, há estudos que avaliam a infraestrutura da integração em termos da liderança exercida pelo Brasil (Simas, 2012); em termos da pertinência desses investimentos na promoção do desenvolvimento econômico regional (Ceceña, 2009; Padula, 2010; Simas, 2012); em termos de se limitar à construção de corredores de exportação e de sua pertinência para integração produtiva (Sarti; Hiratuka, 2010; Calixtre; Barros, 2010); em termos de essa iniciativa levar ao adensamento da conexão física entre os países sul-americanos, permitiria aprofundar o processo de integração econômica entre esses países (Couto, 2007); em termos de críticas à insuficiência de preocupação com a avaliação ambiental dos investimentos (Ceceña et al., 2007); em termos da comparação entre IIRSA e IIRSA-Cosiplan na execução dos projetos e formulação da carteira (Padula, 2015; Costa, Menger, Tancred, 2015; Costa, Menger, Almeida, 2015). Alguns estudos se voltaram para tratar do papel de instituições financeiras regionais como esquemas alternativos de financiamento de longo prazo (e.g. Ocampo, 2006; Deos; Mendonça; Wegner, 2013, Costa; Gonzalez; Almeida, 2014; Tomassian, 2015).

O objetivo principal do artigo é avaliar as condições próprias (em termos de viabilizar) e os mecanismos de financiamento do investimento em infraestrutura física regional no âmbito da carteira da IIRSA-Cosiplan, bem como o entendimento adotado sobre infraestrutura regional. Esse objetivo é parte de uma preocupação mais ampla, isto é, os projetos da carteira IIRSA-Cosiplan representam de fato uma política sul-americana de infraestrutura da integração? A existência de uma carteira que distingue grupos de projetos que devem fortalecer a vinculação entre os territórios dos países da região (API), e dentro desses grupos, projetos individuais, não necessariamente se materializa, dadas as dificuldades de seu financiamento. $\mathrm{O}$ artigo enfatiza BID, CAF e Fonplata porque são atuantes desde os auspícios da inciativa de integração regional de infraestrutura.

Desta feita, na primeira seção, discorre-se sobre o tratamento conceitual dado ao investimento em infraestrutura na literatura e na IIRSA-Cosiplan, bem como sobre o quadro do financiamento da integração econômica regional. Na segunda seção, o foco será a estrutura daquelas instituições em termos de carteira de empréstimos, de indicadores patrimoniais e de principais projetos financiados, bem como sua participação na carteira de investimentos em infraestrutura. Por fim, são apresentadas as considerações finais. 


\section{Infraestrutura e integração econômica regional: caminhos e descaminhos}

A compreensão das operações no âmbito do financiamento dos projetos de infraestrutura IIRSA-Cosiplan requer esclarecimentos do significado de infraestrutura, bem como da complexidade desse tipo de investimento em termos de seu financiamento e execução. Entender tanto a concepção quanto a distribuição dos projetos por país e por setor (transporte, telecomunicações e energia) e as principais fontes de financiamento acessadas pode estreitar a compreensão das restrições enfrentadas por uma iniciativa de integração física regional a qual, entendemos nesse artigo, é um meio para que outros aspectos da integração econômica regional se materializem no longo prazo (e.g. integração produtiva, comercial, social etc). Nesta seção, inicialmente se discorre a respeito da infraestrutura e seu papel para o desenvolvimento econômico e em seguida, descreve-se a carteira de investimentos da IIRSA-Cosiplan, com destaque para as fontes de financiamento. Esta seção, dentro do escopo do artigo, pretende apresentar a carteira de projetos IIRSA-Cosiplan e suas atuais condições de financiamento.

\subsection{IIRSA-Cosiplan: composição e conceito de infraestrutura regional presentes na carteira de projetos de investimento}

A criação da IIRSA se assentou sobre consensos basilares firmados entre os 12 países sul-americanos e as instituições financeiras que compõem o seu Comitê de Coordenação Técnica (CCT). Costa, Gonzalez e Almeida (2014) descrevem, com base em BID (2008), esses consensos como: (i) imperativo avançar na ampliação da escala e do dinamismo do mercado regional e assim nas condições de competição internacional; (ii) superar a carência de infraestrutura física regional representaria um passo fundamental para aprofundar a integração comercial e (iii) imperativo ampliar as fontes de financiamento para aumentar os fluxos de investimento privado e público. Esses consensos apresentados e elaborados pelo BID instituição financeira membro do CCT - condizem com os objetivos e orientações estabelecidos no Comunicado de Brasília quando da criação da IIRSA. Dentre esses objetivos e orientações está: "conceber o futuro espaço econômico da região no âmbito do conceito de eixos de integração e de desenvolvimento (EIDs) econômico e social".

A partir desses consensos o território sul-americano foi tomado como parte de uma estratégia consubstanciada em ações que levariam a aperfeiçoamento da competitividade de cadeias produtivas regionais, pelo menos do ponto de vista logístico. Inicialmente, em 2000, o CCT estabeleceu um Plano de Ações do qual resultou toda a estrutura de funcionamento da IIRSA, isto é: distribuição de projetos por eixos de integração e desenvolvimento (EIDs) e por setores de transporte, energia e telecomunicações sob a estruturação de esquemas financeiros adaptados às especificidades de risco de cada projeto. Para tal, o Plano de Ações estabeleceu outras diretrizes como: a modernização de sistemas regulatórios e institucionais nacionais voltados para normatizar a infraestrutura, bem como harmonizar as políticas e marcos

regulatórios entre os países. O Plano de Ações priorizou EIDs seguindo os seguintes 
Integração e desenvolvimento econômico: estratégias de financiamento do investimento de infraestrutura...

parâmetros: (i) cobertura geográfica de países e regiões, (ii) fluxos de comércio existentes e potenciais; (iii) níveis atuais e volumes projetados de investimentos produtivos; (iv) potencial de atrair a participação do setor privado no financiamento e (v) grau de sustentabilidade ambiental dos projetos $^{2}$ (IIRSA, 2000).

Foram definidos os seguintes eixos: Mercosul-Chile, Andino, Interoceânico, Amazonas, Sul, Escudo Guianês, Peru-Brasil-Bolívia, Hidrovia Paraguai-Paraná, Capricórnio e Andino do Sul (Anexo). A cada eixo foram atribuídos grandes grupos de projetos de investimento que articulam variadas obras para um dado objetivo. Por exemplo, no eixo Amazonas, dentre os grupos de projetos está o Grupo 1 Acesso à Hidrovia do Putumayo, o qual se subdivide em 6 projetos de investimento. A cada um desses 6 projetos são definidas fontes de financiamento das obras, bem como dos estudos de viabilidade e dos estudos de licença ambiental. Com o Cosiplan esses eixos foram mantidos, porém o eixo Amazonas foi ampliado para incluir os territórios das unidades federativas do nordeste do Brasil, os quais, até então, não pertenciam à iniciativa sul-americana de integração física. Dessa forma, praticamente todo o território sul-americano é captado pela carteira de projetos de infraestrutura regional. A área de influência dos EIDs aumentou para $97,7 \%$ do território sul-americano, sendo o eixo Amazonas aquele com maior influência $-8,1 \%$ e Peru-Bolívia-Brasil, com a menor, 1,2\%.

Acordar uma definição, e assim um entendimento, comum no âmbito da IIRSACosiplan sobre o conceito de infraestrutura para a integração física regional poderia representar congruência na definição dos projetos que deverão ser financiados. Demonstraria também os limites de um projeto de infraestrutura, isto é, até aonde esse investimento promove aumento da produtividade e melhor alocação de recursos.

A proximidade geográfica entre os países e as possibilidades de aproveitamento econômico - escoamento de exportações, por exemplo - ajudam a entender a conformação dos EIDs. Os territórios nacionais contemplados com projetos na carteira IIRSA-Cosiplan não são exclusivos para facilitar a conexão física - caso do Brasil no eixo Amazonas, por exemplo. É natural antever que nem todos os projetos de investimento estão voltados para a vinculação de territórios ou para conexão física. Dessa forma, os países possuem interesses e obrigações financeiras distintas na execução da carteira IIRSA-Cosiplan. De longe (Tabela 1), o eixo Mercosul-Chile é aquele com maior participação em número (20,6\%) e custo estimado $(31,8 \%)$. É o eixo que congrega um bloco comercial com uma iminente integração produtiva em marcha entre Brasil e Argentina na indústria automobilística.

(2) Foi Eliezer Batista (1997) que primeiro adotou os conceitos de eixos de desenvolvimento e integração. Eliezer Batista entendia que era necessário um paradigma novo de planejamento dos investimentos em infraestrutura, o qual incluísse uma visão mais abrangente sistêmica e holística do conceito de desenvolvimento. Propunha o reordenamento do desenvolvimento por meio da criação de cinturões que abrigariam redes regionais de transporte, telecomunicações e energia. 
Tabela 1

IIRSA-Cosiplan: caracterização dos eixos de integração e desenvolvimento (EID)

\begin{tabular}{l|c|c|c|c|c|c|c}
\hline Eixo & $\begin{array}{c}\text { Grupos de } \\
\text { projetos }\end{array}$ & $\begin{array}{c}\text { Projetos } \\
\mathrm{n}^{\circ}\end{array}$ & $\begin{array}{c}\text { Investimento } \\
\text { US\$ bilhões }\end{array}$ & $\begin{array}{c}\text { API } \\
\mathrm{n}^{\circ}\end{array}$ & US\$ bilhões \\
\hline Amazonas & 8 & 72 & 12,4 & 27 & 14,1 & 27 & 3,1 \\
\hline Andino & 5 & 81 & 13,9 & 17 & 8,7 & 18 & 8,0 \\
\hline Capricórnio & 2 & 47 & 8,1 & 4,5 & 2,3 & 0 & 0 \\
\hline Sul & 4 & 20 & 3,4 & 4,6 & 2,4 & 6 & 0,9 \\
\hline Escudo Guianense & 5 & 89 & 15,3 & 6,6 & 3,4 & 16 & 1,6 \\
\hline Hidrovia Paraguai-Paraná & 5 & 63 & 10,8 & 11,5 & 6 & 7 & 0,4 \\
\hline Interoceânico Central & 6 & 120 & 20,6 & 61 & 31,8 & 15 & 3,1 \\
\hline Mercosul-Chile & 3 & 24 & 4,1 & 32 & 16,7 & 1 & 0,5 \\
\hline Peru-Brasil-Bolívia & 47 & 581 & 100 & 192 & 100 & 103 & 21 \\
\hline Total & & & & & & 13,6 \\
\hline
\end{tabular}

Fonte: SIP IIRSA-Cosiplan.

Na carteira IIRSA-Cosiplan, há um entendimento para investimento em infraestrutura e outro entendimento para integração ou conexão física. Uma evidência disto é a Agenda de Projetos Prioritários para Integração (API) que materializa o artigo $4^{\circ}$ do Estatuo do Cosiplan ao buscar a conectividade da região por meio da construção e operação eficiente da infraestrutura para sua integração física. É formada por 31 projetos estruturados e 101 projetos individuais distribuídos entre os EIDs (Tabela 1) a partir de sua preponderância naquele quesito. Um projeto estruturado, vale dizer, congrega outros projetos que consolidarão redes de conectividade física com alcance regional. Por exemplo, o projeto API "Carretera Tarapoto - Yurimaguas" é uma parte (uma das obras a ser realizada) do projeto estruturado 3 API "Eje vial Paita - Tarapoto - Yurimagas, Puertos, Centros Logísticos e Hidrovías", no eixo Amazonas. Isto é, este projeto estruturado vai conectar as regiões costeira, de serra e de selva do norte do Peru com o Brasil, pela cidade de Manaus. Em última instância, trata-se da construção de um moderno corredor logístico, na Amazônia e cuja execução exigiu que os governos de Peru e Brasil estabelecessem compromissos conjuntos em prol do desenvolvimento econômico e social da fronteira desses países.

Dessa forma, a definição da carteira de projetos para investimento em infraestrutura se mostra institucional e economicamente complexa. E a harmonização entre os países e as instituições financiadoras - sobretudo aquelas que são o CCT - do entendimento sobre infraestrutura é a diretriz para as ações a serem desenvolvidas na execução dos investimentos. Dentro da institucionalidade IIRSA-Cosiplan, o estabelecimento de conceitos para infraestrutura física regional ocorreu em 2014 durante reunião do Grupo de Trabalho sobre Mecanismos de Financiamento e Garantias (GTMFG) com a presença de delegações de apenas

(3) A lista completa pode ser acessada via SIP - $\underline{\text { http://iirsa.org/proyectos/Proyectos.aspx. }}$ 
Integração e desenvolvimento econômico: estratégias de financiamento do investimento de infraestrutura...

4 países da América do Sul - quais sejam: Argentina, Brasil, Chile, Paraguai - e de instituições financeiras como BID, CAF, Fonplata e BNDES, além do representante do Banco Chinês de Desenvolvimento e do Conselho de Economia e Finanças da Unasul. Logo, essa iniciativa oficialmente existia desde 2000, mas somente em 2014, houve uma discussão sistemática a respeito do conceito de infraestrutura física regional que seria adotado na elaboração e acompanhamento da carteira IIRSA-Cosiplan. Com base nos documentos das reuniões deste Grupo de Trabalho, pode-se afirmar que não se chegou a um consenso sobre qual o conceito que seria usado. Os pontos comuns aos três conceitos estipulados são o objetivo de estimular o fluxo de pessoas, bens e serviços ou informações entre pelo menos dois países da região (Quadro 1). No entanto, com base no SIP (Sistema Informatizado de Projetos), apenas 94 projetos são de âmbito binacional - o equivalente a $16 \%$ da carteira total. Na Agenda de Projetos Prioritários da Integração (API), a participação dos projetos binacionais é proporcionalmente maior, é de $25 \%$ - são 26 projetos de 103 projetos $\mathrm{API}^{4}$.

Quadro 1

IIRSA-Cosiplan - conceitos de infraestrutura para integração regional na América do Sul

\begin{tabular}{|c|c|}
\hline Conceito & Possíveis implicações \\
\hline $\begin{array}{l}\text { Proyecto de infraestructura para la integración regional en América del Sur } \\
\text { es el emprendimiento, conjunto de emprendimientos o proceso institucional } \\
\text { que conecta, amplía o moderniza sistemas de transporte, energía o } \\
\text { comunicaciones, estimulando el flujo de personas, bienes, servicios o } \\
\text { información entre al menos dos países sudamericanos para fomentar el } \\
\text { desarrollo económico y social sostenible. }\end{array}$ & $\begin{array}{l}\text { Focado no empreendimento } \\
\text { em si. Seja apenas um trecho } \\
\text { ou uma obra do projeto que de } \\
\text { fato está conectando dois } \\
\text { países. }\end{array}$ \\
\hline $\begin{array}{l}\text { Proyecto de infraestructura para la integración regional en América del Sur } \\
\text { es uno que se conecta, amplía o moderniza la infraestructura regional, } \\
\text { estimulando el flujo de personas, bienes, servicios o información entre al } \\
\text { menos dos países sudamericanos para fomentar el desarrollo económico y } \\
\text { social sostenible. }\end{array}$ & $\begin{array}{l}\text { Apenas o trecho ao qual o } \\
\text { desembolso se refere. }\end{array}$ \\
\hline $\begin{array}{l}\text { Proyecto de infraestructura para la integración regional es el } \\
\text { emprendimiento que deriva de un proceso de planificación estratégica } \\
\text { multinacional con vistas a la integración de la infraestructura de los países } \\
\text { de América del Sur, de modo que se creen medios para el desarrollo } \\
\text { económico y social sostenible que favorezcan el flujo de personas, bienes, } \\
\text { servicios o información entre al menos dos países de América del Sur. }\end{array}$ & $\begin{array}{l}\text { A atuação dos governos, da } \\
\text { Unasul e das instituições } \\
\text { financeiras regionais é } \\
\text { fundamental para definir a } \\
\text { criação do empreendimento } \\
\text { infraestrutura física. O termo } \\
\text { empreendimento, assim como } \\
\text { no primeiro conceito, } \\
\text { evidencia o reconhecimento da } \\
\text { dificuldade de se avançar na } \\
\text { integração física regional. }\end{array}$ \\
\hline
\end{tabular}

Fonte: Anexo A: Propostas de conceitos de projetos de infraestrutura de integração do GTMFG.

Os pontos diferenciadores dizem respeito à caracterização deste projeto de investimento, isto é, enquanto o segundo conceito apenas menciona que é aquilo que conecta,

(4) Dados condizentes com o último acesso realizado, em dezembro de 2016. 
amplia ou moderniza, o primeiro conceito é mais aprofundado ao afirmar que se trata de um empreendimento, conjunto de empreendimentos ou processo institucional e o terceiro conceito, por sua vez, destaca que se trata de um investimento resultante de planificação estratégica multinacional (Quadro 1). Apenas o primeiro e o terceiro conceitos falam em desenvolvimento econômico regional. Desde as primeiras tratativas que levaram à criação da IIRSA até sua incorporação, em 2009, a um foro de integração regional propriamente dita, adotou-se uma visão compartimentada dos projetos de infraestrutura.

Em linha geral, infraestrutura é o suporte ou a base de quaisquer outros investimentos (produtivos), sejam esses de fonte pública ou privada. Constitui a construção de instrumentos o que pode ocorrer sob uma perspectiva atinente à eficiência de mercado ou sob uma perspectiva de provisão de bens públicos. As primeiras teorizações sobre investimento em infraestrutura, na década de 1960, o colocavam como instrumento para equalização de preços de insumos ou 'capital material público' (Jochimsen, 1966 apud Buhr, 2003), o que não se concretizou. Entre 1960 e 1980, os estudos que buscaram traçar um conceito para infraestrutura foram muitos (Buhr, 2003). Buscava-se por um conceito que simultaneamente tratasse de quais bens estão incluídos em investimento em infraestrutura, se sua natureza é estatal ou privada e dos seus efeitos possíveis no desenvolvimento e crescimento econômicos. Buhr (2003) avalia que infraestrutura e desenvolvimento econômico estão relacionados somente se houver complementaridades material, institucional e de 'bem público'. As funções essenciais da infraestrutura dizem respeito a sua influência nos custos das firmas e na provisão de serviços às famílias.

Essencialmente, a infraestrutura é o investimento que harmonizaria interesses individuais dentro de uma dada comunidade sem representar uma solução única para problemas dessa comunidade. Na América do Sul, a julgar pelos conceitos apresentados (Quadro 1), a carteira de investimentos pensada por instituições financeiras regionais (CCT da IIRSA) estaria mais atenta à dinâmica da integração na medida em que os interesses regionais - de comércio e de investimentos direto externos - se sobrepusessem a demandas nacionalizadas por infraestrutura.

\subsection{Mecanismos institucionais de financiamento da carteira de projetos IIRSA-Cosiplan: descrição e perspectivas}

Essa carteira em 2007 apresentava 348 projetos ao montante de US\$ 38 bilhões (Simas, 2012) passando a 581 projetos ao montante de 192 bilhões, em 2016. Esse crescimento não indica, necessariamente, que a conexão logística entre os países sul-americanos tenha de fato ocorrido. Os projetos em etapa "perfil" (Tabela 2) totalizam 123 (21\% da carteira total) e a maioria desses projetos em "perfil" (90\%) está estagnada nessa etapa há pelo menos 4 anos, sendo que 37 desses projetos estão em "perfil" desde 2004 (Cosiplan, 2016). A conclusão, por conseguinte, é que sua execução tem sido morosa, esbarrando em aspectos peculiares a um investimento de infraestrutura e, principalmente, no seu financiamento. A inclusão do Cosiplan, em 2009, ocorreu também sob a justificativa de que a IIRSA falhara no âmbito da 
Integração e desenvolvimento econômico: estratégias de financiamento do investimento de infraestrutura...

atração de novas fontes de financiamento que não onerassem os gastos públicos dos países da América do Sul (Costa, Menger, Tancredi, 2015). Porém, passados 8 anos dessa modificação de institucionalidade, os dados da Tabela 2 sugerem que é exagero afirmar que ela promoveu uma transformação na conclusão dos projetos de investimento em infraestrutura.

Tabela 2

IIRSA-Cosiplan: Etapas do projeto de infraestrutura e o acesso ao financiamento (2016)

\begin{tabular}{|c|c|c|c|c|c|c|}
\hline \multirow[b]{2}{*}{ Etapa } & \multirow[b]{2}{*}{$\begin{array}{c}\text { Ações relacionadas - } \\
\text { descrição }\end{array}$} & \multicolumn{5}{|c|}{ Projetos - características } \\
\hline & & $\begin{array}{l}\text { Número } \\
\text { de } \\
\text { projetos }\end{array}$ & Valor & $\begin{array}{c}\text { Número de } \\
\text { projetos com } \\
\text { Financiamento } \\
\text { público } \\
\end{array}$ & $\begin{array}{c}\text { Âmbito } \\
- \\
\text { nacional }\end{array}$ & $\begin{array}{c}\text { Setor } \\
\text { Transporte }\end{array}$ \\
\hline Perfil & $\begin{array}{c}\text { Estudos de conveniência e } \\
\text { de factibilidade técnico- } \\
\text { econômica }\end{array}$ & $21 \%$ & $20 \%$ & $91 \%$ & $77 \%$ & $19 \%$ \\
\hline \multirow{3}{*}{$\begin{array}{c}\text { Pré- } \\
\text { execução }\end{array}$} & $\begin{array}{l}\text { Prefactibilidade: exame } \\
\text { detalhado das } \\
\text { características apontadas } \\
\text { em perfil }\end{array}$ & \multirow{3}{*}{$26 \%$} & \multirow{3}{*}{$25 \%$} & \multirow{3}{*}{$84 \%$} & \multirow{3}{*}{$79 \%$} & \multirow{3}{*}{$25 \%$} \\
\hline & $\begin{array}{l}\text { Factibilidade: exame } \\
\text { detalhado e preciso da } \\
\text { alternativa escolhida em } \\
\text { "perfil" que contemple } \\
\text { factibilidade e rentabilidade }\end{array}$ & & & & & \\
\hline & $\begin{array}{c}\text { Investimento: (i) } \\
\text { financiamento - acordos e } \\
\text { trâmites destinados à } \\
\text { obtenção de fundos de } \\
\text { financiamento e (ii) estudos } \\
\text { de engenharia }\end{array}$ & & & & & \\
\hline Execução & $\begin{array}{c}\text { Conjunto de atividades } \\
\text { necessárias para execução } \\
\text { da obra de infraestrutura. }\end{array}$ & $30 \%$ & $30 \%$ & $76 \%$ & $89 \%$ & $28 \%$ \\
\hline Conclusão & Conclusão. & $22 \%$ & $15 \%$ & $78 \%$ & $84 \%$ & $18 \%$ \\
\hline \multicolumn{2}{|c|}{ Número total de projetos na carteira } & 581 & $\begin{array}{l}\text { US\$ } \\
192 \text { bi }\end{array}$ & 475 & 482 & 518 \\
\hline
\end{tabular}

Fonte: http://iirsa.org/proyectos/Principal.aspx\#

A ficha de caracterização de 30\% dos projetos da carteira ativa (453 em 2016) passou a apresentar, nos últimos anos, a data prevista de conclusão. Considerando esses projetos que apresentam essa informação, pelo menos $85 \%$ serão concluídos nos próximos 5 anos, totalizando US $\$ 538$ bilhões a serem investidos. Entre 2016 e 2020 haverá uma aceleração da conclusão dos projetos e até 2026 eles deverão estar concluídos. Por exemplo, o projeto "Mejoramiento del Puerto de Arica" - do eixo Interoceânico Central no Chile com 
financiamento privado/corporativo - tem data estimada de finalização para 31 de dezembro de 2018. Por outro lado, há um bom número de projetos cuja finalização é impossível de estimar, pois não contam com fonte de financiamento definida (22\% da carteira ativa). É válido ressaltar que essa data de conclusão do projeto é estimada pelo País no qual o investimento será realizado. Da mesma forma que os trâmites para acerto do financiamento - fontes, garantias, prazo, etc.

Infraestrutura de conexão regional pressupõe a construção de rodovias, hidrelétricas e cabeamento de telecomunicações que interligue pelo menos dois países. Na atual carteira (Tabela 2), porém, apenas $16 \%$ dos investimentos previstos na carteira são binacionais (97 projetos) e $0,74 \%$ trinacionais (4 projetos). Na prática, conforme observação dos projetos da carteira, o entendimento de infraestrutura no âmbito da IIRSA-Cosiplan engloba a vinculação de territórios entre países e também dentro de um mesmo país. Uma crítica recorrente (Padula, 2015) é o deslocamento da integração regional para projetos nacionais (e aí estaduais e até municipais) de infraestrutura. Isso mesmo havendo expansão da carteira de projetos ao longo da gestão da Cosiplan. Em 2014, estavam previstos 419 projetos e, em 2015, 593 projetos e em 2016, 581 projetos. Transportes é o setor com maior número de projetos concluídos, em andamento e em análise - a carteira ativa (Tabela 2).

Após definidas fonte e tipo de financiamento, os desembolsos realizados serão determinantes para que as obras dos projetos avancem, sendo as suas fases descritas na Tabela 2. Os desembolsos, respeitadas as fontes de financiamento, começam a se desenrolar na préexecução, somente. A dinâmica dos desembolsos e da execução das obras é peculiar a cada projeto. Por exemplo, o projeto "adequação do porto de El Carmen", do Eixo Amazonas, de âmbito nacional e do setor de transportes, teve custo previsto de US\$ 3 milhões e financiamento público, via Tesouro Nacional, estimado. No entanto, ainda não foi iniciado e se encontra, por isso, na etapa "perfill". Infelizmente, a base de informações IIRSA não disponibiliza o ano de início das obras de praticamente todos os projetos, impossibilitando a montagem de um fluxo de evolução dos projetos ao longo do tempo. Ainda assim, busca-se na Tabela 2 caracterizar os projetos de infraestrutura regional a partir das suas etapas e, assim, do seu financiamento.

Um projeto de investimento em infraestrutura envolve diferentes frentes que não somente a da sua execução em si. O acompanhamento da evolução da carteira de projetos da integração física sul-americana destaca com frequência o número de projetos em suas respectivas etapas. A política regional de infraestrutura se esgota na carteira de projetos IIRSACosiplan, logo, aos objetivos de cada projeto obedecendo os aspectos setoriais e a agenda prioritária de integração (API). Dessa forma, os aspectos subjacentes à execução de um projeto desse tipo - tais como o financiamento - vão sendo pensados à medida que se avança na carteira. Lakshmanan (1989) e Diewert (1986) destacam algumas características da infraestrutura que expõem a sua complexidade, sendo eles de ordem técnica: são investimentos 
Integração e desenvolvimento econômico: estratégias de financiamento do investimento de infraestrutura...

de pouca mobilidade espacial, de baixa substitubilidade cujo produto final é um insumo de produção e de ordem econômica: apresentam elevado custo fixo, retornos crescentes de escala em larga operação e elevado risco fixo de investimento. Nas características de ordem econômica, fazem parte a criação privada de efeitos de externalidade, por exemplo, a construção de uma hidrelétrica.

Tais características contribuem para afirmar que o investimento em infraestrutura exerce influência na decisão privada de investir, bem como promove um aumento dos retornos dos insumos privados. Dessa forma, o investimento em infraestrutura impacta diretamente o crescimento econômico, porque contribui para aumentar a produtividade da economia (Reis, 2007). Contudo, implica a aquisição de bens duráveis que possuem um elevado preço de oferta, indivisibilidades e são de grande escala, ou seja, não podem ser convertidos em dinheiro a qualquer tempo (são 'ilíquidos'). O investimento em infraestrutura, na sua fase de implementação, possui um custo irrecuperável, ou seja, caso a obra não seja concluída, o investidor não poderá recuperar o montante investido (Correa, 2010). Ainda assim, após concluído, seu fluxo de caixa é lento, mas a expectativa de rentabilidade futura é mais estável.

Essas características se consubstanciam em desafios para financiamento de longo prazo, ainda mais ao envolver países diferentes, com sistemas financeiros diferentes. Sem um entendimento comum ou sem uma política regional comum para infraestrutura, que considere a conexão física entre os países sul-americanos, o financiamento tem ocorrido projeto a projeto. A maior parte dos projetos é de âmbito nacional, o que exime de negociações bilaterais as decisões sobre o financiamento. O Brasil é apontado como a liderança natural dessa iniciativa (Carneiro, 2009). É a economia com parque industrial e pauta exportadora mais diversificados, bem como maior extensão territorial entre os países sul-americanos. Argentina apresenta maior número de projetos na carteira total, seguida do Brasil, do Chile, do Peru e do Paraguai (Tabela 3). O Paraguai, embora uma das economias menores da América do Sul, é um grande produtor de grãos, como a soja. Nessa mesma linha, Argentina, Brasil, Chile e Peru são as economias com maior PIB da região ${ }^{5}$, bem como são grandes exportadoras de commodities, notadamente.

A descrição da carteira IIRSA-Cosiplan ocorrerá, nesta seção, sob os eixos de integração e desenvolvimento (EID) e as condições de arranjos de financiamento caracterizadoras. De modo geral, o tipo de financiamento público-privado deveria representar uma das grandes inovações de financiamento de longo prazo dos projetos desta carteira, no entanto, apenas $6 \%$ da carteira total é ou foi financiada nesses moldes. Brasil e Peru se destacam com maior número de projetos financiados sob as parcerias público-privadas (Tabela 3).

(5) Em 2015, com base em dados Cepalstat, Argentina, Brasil, Chile e Peru representaram 85\% do PIB anual em dólares e a preços correntes, sendo que só o Brasil representou 53\%. A taxa de crescimento do PIB anual total anual a preços correntes de 2015, por sua vez, revela que as economias que mais cresceram neste ano foram Bolívia (4,8\%), Peru (3,3\%), Colômbia (3,1\%). 
Tabela 3

IIRSA-Cosiplan: distribuição de projetos por país e custo estimado do investimento (2016)

\begin{tabular}{|c|c|c|c|c|c|c|}
\hline \multirow{4}{*}{ País } & \multirow{2}{*}{\multicolumn{4}{|c|}{ Carteira }} & \multicolumn{2}{|c|}{ Tipo de financiamento } \\
\hline & & & & & Público & Público-privado \\
\hline & \multicolumn{2}{|c|}{ Projetos } & \multicolumn{2}{|c|}{ Custo do Investimento } & \multicolumn{2}{|c|}{ Projetos } \\
\hline & $\left(\mathrm{n}^{\mathrm{o}}\right)$ & $(\%)$ & US\$ milhões & $(\%)$ & $\left(\mathrm{n}^{\mathrm{o}}\right)$ & $\left(\mathrm{n}^{\circ}\right)$ \\
\hline Argentina & 178 & $26 \%$ & 48.921 & $22 \%$ & 174 & 3 \\
\hline Bolívia & 52 & $8 \%$ & 10.578 & $5 \%$ & 50 & 1 \\
\hline Brasil & 94 & $14 \%$ & 82.413 & $37 \%$ & 75 & 8 \\
\hline Chile & 73 & $11 \%$ & 16.105 & $7 \%$ & 50 & 1 \\
\hline Colômbia & 33 & $5 \%$ & 4.743 & $2 \%$ & 29 & 4 \\
\hline Equador & 40 & $6 \%$ & 19.609 & $9 \%$ & 40 & 0 \\
\hline Guiana & 8 & $1 \%$ & 911 & $0 \%$ & 6 & 2 \\
\hline Paraguai & 66 & $10 \%$ & 18.002 & $8 \%$ & 59 & 2 \\
\hline Peru & 73 & $11 \%$ & 11.802 & $5 \%$ & 34 & 11 \\
\hline Suriname & 7 & $1 \%$ & 3.832 & $2 \%$ & 5 & 2 \\
\hline Uruguai & 42 & $6 \%$ & 5.545 & $2 \%$ & 34 & 4 \\
\hline Venezuela & 20 & $3 \%$ & 2.109 & $1 \%$ & 18 & 1 \\
\hline Total & $686^{*}$ & $100 \%$ & $224.570 * *$ & $100 \%$ & $84 \%$ & $6 \%$ \\
\hline
\end{tabular}

*De fato a carteira é formada de 581 projetos, porém, para fins de financiamento, um mesmo projeto pode ser subdividido em mais de uma obra, o que explica esse número de 686 projetos. **Idem para o custo total do investimento.

Fonte: Elaboração própria a partir da base Fonte: SIP - IIRSA.

A multinacionalização, em meados da década de 2000, das maiores empresas brasileiras, sobretudo as estatais, tornou países sul-americanos hospedeiros iniciais para investimentos de empresas como Eletrobrás, Petrobrás, dentre outras como as construtoras Andrade Gutierrez, Camargo Correa, Odebrecht e OAS (Deos et al., 2010; Simas, 2012). Nesse contexto, as parcerias público-privadas foram tomadas a desempenhar um papel facilitador. O Peru recebeu expressivos volumes de investimento de empreiteiras brasileiras na execução de obras de infraestrutura. Odebrecht ao lado de Graña e Montero formou a Concessionária IIRSA Norte, a qual é a principal executora das obras dos 11 projetos em parceria público-privada (Tabela 3). Por exemplo, o projeto API “Carretera Tarapoto-Yurimaguas" de âmbito nacional, concluído em 2013, teve financiamento de US\$ 179 milhões de agentes privados/corporativos - 77\% do custo total do investimento. BID e Tesouro Nacional garantiram o restante, sendo que a CAF participou do grupo de agentes privados/corporativos sob uma linha de crédito de US\$ 60 milhões entre Estado peruano e a Concessionária IIRSA Norte. O Banco Nacional de Desenvolvimento Econômico e Social (BNDES) ${ }^{6}$ financiou a internacionalização das

(6) O BNDES incorporou em sua missão, desde 2003, este objetivo estratégico, qual seja, de atuar como órgão financiador da integração da América do Sul, quer apoiando as exportações de bens e serviços para a região, quer apoiando os investimentos diretos de empresas brasileiras, ou mesmo financiando a integração da infraestrutura regional (Deos et al., 2010). 
Integração e desenvolvimento econômico: estratégias de financiamento do investimento de infraestrutura...

empresas brasileiras. Essa sua atuação cresceu consideravelmente entre 2001 e 2012: em 2001 os desembolsos do BNDES para infraestrutura foram de US\$ 92 milhões e em 2012, US\$ 792 milhões.

O Banco, na carteira IIRSA-Cosiplan, consta como fonte de financiamento de apenas 2 projetos (Tabela 4). Ambos de âmbito nacional na Bolívia. O primeiro projeto "Culminación de pavimentación Potosí-Tarija", em execução, é uma rodovia ao sul da Bolívia que é um dos trechos da Rodovia Panamericana que ligará Bolívia e Argentina. O BNDES concluiu, o financiamento do trecho "Chuchu Ingenio - San Lorenzo" de US\$ 90 milhões, em torno de $38 \%$ do custo total deste investimento. O segundo projeto "Pavimentación Potosí - Tupiza Villazón", em execução, é uma rodovia de vinculação do sudoeste da Bolívia, representando uma via alternativa de escoamento de bens para Argentina. O BNDES concluiu o financiamento de US\$ 67 milhões (37\% do custo total) do trecho "Bella Vista - Vitichi Cotagaita". Foi um financiamento público, isto é, o BNDES atuou junto ao Tesouro Nacional da Bolívia, em parceria com a CAF.

As fontes de financiamento da carteira IIRSA-Cosiplan vão desde os Tesouros Nacional, Estadual e Municipal até instituições como JBIC e até União Europeia (Tabela 4). Só o Tesouro Nacional representa $61 \%$ enquanto os bancos privados, em torno de $1 \%$. Os esquemas binacionais representam apenas $2 \%$. E até mesmo instituições como BID, CAF e Banco Mundial representam 10\%, aproximadamente. A diversificação de fontes de financiamento seria uma forma se chegar à execução dos projetos de investimento sem depender apenas de recursos públicos nacionais, estaduais ou municipais e de instituições financeiras internacionais tradicionais, como o BID e o Grupo Banco Mundial. A liderança brasileira no processo regional de integração econômica, como destaca Furtado (2008), foi impondo entraves para a consolidação desse Banco, sobretudo quanto ao uso de reservas internacionais dos países como fonte de recursos. Por outro lado, não se aprofundaram iniciativas institucionalmente novas de financiamento de longo prazo na região.

O governo chinês financia o Tesouro Nacional da Argentina em 3 projetos individuais (Tabela 4) dos 9 projetos individuais do projeto estruturante "Corredor Ferroviario Bioceánico Paranaguá-Antofogasta". Esse projeto estruturante visa renovar linhas férreas interconectando assim Brasil, Paraguai, Argentina e Chile constituindo uma linha férrea que ligará o oceano Atlântico ao Pacífico pelos países do Cone Sul. O escoamento de mercadorias (a granel - grãos e minérios) pelo oceano Pacífico é a principal justificativa desse projeto estruturante. $\mathrm{O}$ governo chinês está desembolsando US\$ 2,5 bilhões para executar mais mil quilômetros de novas vias no trajeto entre a fronteira da Argentina com o Paraguai até a fronteira da Argentina com o Chile (noroeste). Para essas obras o governo chinês estabeleceu, em 2014, contrato com a empresa chinesa Cemec (China Machiney Engineering Wuxi Co. Ltda.) por um período de 4 anos. A operação de financiamento e a de prestação de serviços pela Cemec (renovação e construção das linhas férreas) foi acompanhada da assinatura por China e Argentina do memorando de entendimento para estabelecer um sistema de liquidação de yuans no mercado argentino. 
Tabela 4

IIRSA-Cosiplan: fontes de financiamento da carteira ativa (2016)

\begin{tabular}{|c|c|c|c|c|}
\hline Fonte & Tipo & Projetos & $\%$ & US\$ milhões \\
\hline Bancos privados & Público-privado & 4 & $1 \%$ & 1.303 \\
\hline BID & Público & 39 & $7 \%$ & 10.382 \\
\hline Binacional & Público & 13 & $2 \%$ & 9.660 \\
\hline BNDES & Público & 2 & $0 \%$ & 419 \\
\hline \multirow{2}{*}{ CAF } & Público & 25 & $4 \%$ & 6.069 \\
\hline & Público-privado & 5 & $0,8 \%$ & 2.115 \\
\hline \multirow{2}{*}{ FOCEM } & Público & 8 & $1,3 \%$ & 1.294 \\
\hline & Público-privado & 2 & $0,7 \%$ & 0,411 \\
\hline FONPLATA & Público & 6 & $1 \%$ & 769 \\
\hline Governo Chinês & Público & 3 & $1 \%$ & 400 \\
\hline Grupo Banco Mundial & Público & 3 & $1 \%$ & 793 \\
\hline JBIC & Público & 3 & $1 \%$ & 189 \\
\hline \multirow{2}{*}{ Privados/corporativo } & Privado & 65 & $11 \%$ & 34.521 \\
\hline & Público-Privado & 23 & $4 \%$ & 33.615 \\
\hline Tesouro Municipal & Público & 2 & $0 \%$ & 2.731 \\
\hline Tesouro Nacional & Público & 352 & $61 \%$ & 95.700 \\
\hline Tesouro Estadual & Público & 18 & $3 \%$ & 6.125 \\
\hline União Europeia & Público & 2 & $1 \%$ & 101 \\
\hline \multirow[t]{2}{*}{ Vários } & Público-Privado & 8 & $1,7 \%$ & 2.817 \\
\hline & & 592 & $100 \%$ & 213.038 \\
\hline
\end{tabular}

Fonte: Elaboração própria a partir da base de dados SIP - IIRSA.

O financiamento por agentes privados/corporativos ocorre essencialmente no esquema de concessão de infraestrutura de transportes, notadamente (Tabela 5). O financiamento totalmente privado totaliza 65 projetos a US\$ 35 bilhões, dos quais, 25 estão em execução ( $40 \%$ do montante total), 15 em pré-execução ( $29 \%$ do montante total), 7 em fase perfil (17\% do montante total) e 18 projetos foram concluídos (11\%). O eixo de integração e desenvolvimento Mercosul-Chile é aquele com maior número de projetos com essa modalidade de financiamento. É o eixo com as economias com parque industrial e tecnológico mais diversificado e que já apresentam um processo de integração produtivo em andamento. Em alguns casos, como os projetos no Brasil, representam processos de privatização de rodovias e de aeroportos. São projetos nacionais que podem facilitar o escoamento de mercadorias e em alguma medida a interligação entre os países fronteiriços - especialmente no caso de renovação e melhorias de postos alfandegários (passos de fronteira). 
Integração e desenvolvimento econômico: estratégias de financiamento do investimento de infraestrutura...

Tabela 5

IIRSA-Cosiplan: empresas concessionárias em financiamento privado de projetos em execução (2016)

\begin{tabular}{|c|c|c|c|c|c|c|}
\hline Eixo & Projeto & País & Empresa & $\begin{array}{c}\text { US\$ } \\
\text { milhões }\end{array}$ & Ano & Prazo \\
\hline \multirow{6}{*}{ Amazonas } & $\begin{array}{l}\text { Rehabilitación del } \\
\text { Aeropuerto de Piura }\end{array}$ & Peru & $\begin{array}{c}\text { Consorcio GBH - } \\
\text { Swissport Aeropuertos } \\
\text { (ADP) }\end{array}$ & 7 & 2006 & 25 \\
\hline & Aeropuerto De Pucallpa & Peru & $\begin{array}{c}\text { Consorcio GBH - } \\
\text { Swissport Aeropuertos } \\
\text { (ADP) }\end{array}$ & 9 & 2006 & 25 \\
\hline & $\begin{array}{l}\text { Modernización Del } \\
\text { Puerto De El Callao } \\
\text { (Nuevo Muelle De } \\
\text { Contenedores) } \\
\end{array}$ & Peru & $\begin{array}{c}\text { Consorcio Terminal } \\
\text { Internacional De } \\
\text { Contenedores Del Callao* }\end{array}$ & 705 & 2006 & 30 \\
\hline & $\begin{array}{c}\text { Autopista Lima - Ricardo } \\
\text { Palma }\end{array}$ & Peru & Rutas de Lima S.A.C. & 200 & 2013 & 30 \\
\hline & $\begin{array}{c}\text { IIRSA Centro, Tramo 2: } \\
\text { Ricardo Palma - La } \\
\text { Oroya - Desvío Cerro De } \\
\text { Pasco / La Oroya - } \\
\text { Huancayo }\end{array}$ & Peru & $\begin{array}{c}\text { Consorcio Desarrollo Vial } \\
\text { de los Andes } \\
\text { (DEVIANDES) }^{* *}\end{array}$ & 100 & 2010 & 25 \\
\hline & $\begin{array}{c}\text { Ferrovía Nova } \\
\text { Transnordestina Fase I } \\
\text { (Suape - } \\
\text { Salgueiro/Pecém - Eliseu } \\
\text { Martins) }\end{array}$ & Brasil & Concessionária TLSA & 3.000 & 2014 & - \\
\hline \multirow[b]{2}{*}{ Andino } & $\begin{array}{c}\text { Planta Carboeléctrica De } \\
\text { Santo Domingo }\end{array}$ & $\begin{array}{c}\text { Venezue } \\
\text { la }\end{array}$ & -- & 625 & -- & -- \\
\hline & $\begin{array}{c}\text { Construcción De La } \\
\text { Segunda Calzada En El } \\
\text { Tramo Cerro Azul - Ica } \\
\end{array}$ & Peru & COVIPERU S.A. & 294 & 2005 & 30 \\
\hline Do Sul & $\begin{array}{c}\text { Modernización Del } \\
\text { Puerto De Talcahuano }\end{array}$ & Chile & $\begin{array}{l}\text { Talcahuano Terminal } \\
\text { Portuario S.A. (TTP) }\end{array}$ & 53 & 2012 & 30 \\
\hline $\begin{array}{l}\text { Hidrovia } \\
\text { Paraguai- } \\
\text { Paraná }\end{array}$ & $\begin{array}{c}\text { BR-277: Santa Terezinha } \\
\text { De Itaipú - Cascavel }\end{array}$ & Brasil & $\begin{array}{l}\text { Concessionária } \\
\text { Ecocataratas }\end{array}$ & 5 & 1997 & 24 \\
\hline \multirow{3}{*}{$\begin{array}{l}\text { Inter- } \\
\text { oceânico } \\
\text { Central }\end{array}$} & $\begin{array}{c}\text { Mejoramiento Del Puerto } \\
\text { De Arica }\end{array}$ & Chile & Empresa Portuaria Arica & 62 & -- & -- \\
\hline & $\begin{array}{c}\text { Mejoramiento Del Puerto } \\
\text { De Iquique }\end{array}$ & Chile & SAAM e Dragados & 180 & 2000 & -- \\
\hline & $\begin{array}{c}\text { Mejoramiento Del } \\
\text { Aeropuerto De Tacna }\end{array}$ & Peru & $\begin{array}{c}\text { Consorcio Aeropuertos } \\
\text { Andinos } \\
\end{array}$ & 52 & 2011 & 25 \\
\hline
\end{tabular}

Continua... 
Tabela 5 - Continuação

\begin{tabular}{|c|c|c|c|c|c|c|}
\hline Eixo & Projeto & País & Empresa & $\begin{array}{c}\text { US\$ } \\
\text { milhões }\end{array}$ & Ano & Prazo \\
\hline \multirow{10}{*}{$\begin{array}{l}\text { Mercosul- } \\
\text { Chile }\end{array}$} & $\begin{array}{l}\text { Ampliación Del } \\
\text { Aeropuerto De Campinas }\end{array}$ & Brasil & $\begin{array}{c}\text { Concessionária } \\
\text { Aeroportos Brasil } \\
\text { Viracopos } * * * \\
\end{array}$ & 3.550 & 2012 & 30 \\
\hline & $\begin{array}{l}\text { Ampliación Del } \\
\text { Aeropuerto De Guarulhos }\end{array}$ & Brasil & $\begin{array}{c}\text { Invepar e Airports } \\
\text { Company South Africa } \\
\text { (ACSA) }\end{array}$ & 1.900 & 2012 & 20 \\
\hline & $\begin{array}{c}\text { Conclusión De La } \\
\text { Duplicación Del Tramo } \\
\text { San Pablo - Curitiba } \\
\text { (BR-116 / SP) }\end{array}$ & Brasil & $\begin{array}{l}\text { Concessionária Autopista } \\
\text { Régis Bittencourt S/A }\end{array}$ & 350 & 2000 & 25 \\
\hline & $\begin{array}{c}\text { Ruta Internacional CH-60 } \\
\text { (Sector Valparaíso - Los } \\
\text { Andes) }\end{array}$ & Chile & $\begin{array}{c}\text { Sociedad } \\
\text { Concesionaria Autopista } \\
\text { de los Andes S.A. }\end{array}$ & 447 & -- & -- \\
\hline & $\begin{array}{c}\text { Mejoras En El Puerto De } \\
\text { San Antonio }\end{array}$ & Chile & $\begin{array}{c}\text { Empresa Portuaria de San } \\
\text { Antonio; Puerto Panul; } \\
\text { Puerto Central (PCE) }\end{array}$ & 370 & -- & -- \\
\hline & $\begin{array}{c}\text { Instalación De Planta De } \\
\text { Regasificación De Gas } \\
\text { Natural Licuado (GNL) } \\
\text { En Uruguay }\end{array}$ & Uruguai & Gas Sayago (GSSA) & 1.125 & \multicolumn{2}{|c|}{$\begin{array}{c}\text { Obras } \\
\text { suspensas }\end{array}$} \\
\hline & $\begin{array}{l}\text { Ampliación Del } \\
\text { Aeropuerto Arturo } \\
\text { Merino Benitez } \\
\text { (Santiago) }\end{array}$ & Chile & $\begin{array}{c}\text { Sociedad Concesionaria } \\
\text { Nuevo Pudahuel S.A. } \\
\text { (SCNP) }\end{array}$ & 590 & 2015 & 15 \\
\hline & $\begin{array}{c}\text { Ampliación Del Puerto } \\
\text { Valparaiso }\end{array}$ & Chile & $\begin{array}{l}\text { Terminal Pacífico Sur } \\
\text { (TPS) - Terminal 1; } \\
\text { Terminal Cerros de } \\
\text { Valparaíso (TCVAL) - } \\
\text { Terminal } 2 \\
\end{array}$ & 560 & -- & -- \\
\hline & $\begin{array}{l}\text { Nuevo Complejo } \\
\text { Fronterizo Los } \\
\text { Libertadores } \\
\text { (Optimización Sistema } \\
\text { Cristo Redentor) }\end{array}$ & Chile & $\begin{array}{c}\text { Em 2014, } 3 \text { empresas } \\
\text { apresentaram propostas: } \\
\text { Besalco, Concesiones BT } \\
\text { e Concesiones Viarias } \\
\text { Chile }\end{array}$ & 76 & -- & -- \\
\hline & $\begin{array}{c}\text { Terminal Portuaria En La } \\
\text { Charqueada Y Dragado } \\
\text { Del Río Cebollati }\end{array}$ & Uruguai & -- & 7 & -- & -- \\
\hline \multirow{2}{*}{$\begin{array}{l}\text { Peru- } \\
\text { Brasil- } \\
\text { Bolívia }\end{array}$} & $\begin{array}{c}\text { Mejoramiento del } \\
\text { Aeropuerto de Puerto } \\
\text { Maldonado }\end{array}$ & Peru & $\begin{array}{l}\text { Consorcio Aeropuertos } \\
\text { Andinos del Perú }\end{array}$ & 42 & 2011 & 25 \\
\hline & $\begin{array}{c}\text { Mejoramiento Del } \\
\text { Aeropuerto De Arequipa }\end{array}$ & Peru & $\begin{array}{c}\text { Consorcio Aeropuertos } \\
\text { Andinos del Perú }\end{array}$ & 51 & 2011 & 25 \\
\hline
\end{tabular}

Fonte: SIP - IIRSA. 
Integração e desenvolvimento econômico: estratégias de financiamento do investimento de infraestrutura...

O financiamento da carteira IIRSA-Cosiplan por parcerias público-privadas ou com financiamento privado, algumas delas apresentadas na Tabela 5, na avaliação de Tomassian (2015), têm sido apresentadas como a única possibilidade de execução e de conclusão dos projetos desta carteira, visto que as economias sul-americanas de tempos em tempos enfrentam restrições fiscais que as impedem de financiar com recursos públicos investimentos desta magnitude. Nos primeiros anos da iniciativa para integração por infraestrutura (IIRSA), as economias sul-americanas empreenderam medidas de restrição fiscal que prejudicaram a capacidade de financiamento da IIRSA. É a partir do biênio 2005-2006 - após o Brasil negociar com o FMI o Plano Piloto de Investimentos (PPI) que viria a constituir o Plano de Aceleração do Crescimento (PAC) - que os projetos de investimento em infraestrutura começam a se concretizar (Honório, 2013). E nos últimos anos, novamente, essas economias adotam medidas de restrição fiscal. Embora representem uma solução em termos de financiamento de longo prazo, a atuação dos agentes privados no financiamento da carteira IIRSA-Cosiplan requer forte capacidade institucional dos países para selecionar e ceder a concessão.

A gestão do financiamento de longo prazo desta carteira de projetos ainda carece de acertos entre os países quanto aos parâmetros para constituição das carteiras de projetos. $\mathrm{O}$ Grupo de Trabalho sobre Mecanismos de Financiamento e Garantias (GTMFG) só mais recentemente avançou em direção a uma definição sobre infraestrutura e elementos decisivos como garantias para o financiamento, bem como concessões (rentabilidade) ainda carecem de definições comuns. Cabe a cada um dos países definir os critérios de financiamento. Nesses critérios se incluem o processo de empréstimo junto a instituições financeiras internacionais, bem como obter garantias junto a instituições também financeiras internacionais ou o Convênio de Créditos e Pagamentos Recíprocos (CCR). O Brasil, por exemplo, segue o Decreto 4.992 de 18 de fevereiro de 2004. O financiamento de projetos de investimento com recursos de instituições financeiras internacionais ocorrerá com a realização de seus desembolsos à Conta Especial ou Conta Empréstimos em favor do Tesouro Nacional brasileiro até que o fundo rotativo do projeto esteja com saldo zerado. Projetos internacionais também devem criar uma unidade gestora (UG) registrada no Sistema Integrado de Administração Financeira (Siafi). As definições a respeito da concessão dos investimentos também carecem de um entendimento comum. Atualmente, a concessão ocorre no âmbito da legislação de cada um dos países para licitações. $\mathrm{Ou}$, sob a criação de empresas estatais específicas para controle e operação desses investimentos como o fez a Argentina - criou a Trenes Argentinos - Carga y Logística.

$\mathrm{Na}$ perspectiva dos princípios norteadores dessa iniciativa, bancos privados manifestaram interesse e em alguma medida se envolveram no financiamento de projetos nos primeiros anos. Entretanto, como elucida Honório (2013), os países em função de suas restrições fiscais não procuravam empréstimos e a intenção dos bancos - privados, bem como $\mathrm{BID}$ e CAF - de montar uma carteira de projetos a financiar não ocorreu. Em outras palavras, os bancos privados e também as instituições financeiras multilaterais somente emprestariam se os países sul-americanos apresentassem capacidade de endividamento. Uma explicação, ressaltada por Honório (2013), com base em estudo do Ministério do Planejamento do Brasil, 
para os bancos e demais instituições financeiras não se envolverem no financiamento dos projetos da carteira foi os países da região terem priorizado o financiamento de seus projetos nacionais de infraestrutura em detrimento daqueles de integração, mesmo quando suas condições de endividamento melhoraram.

Nessa perspectiva, ainda não está clara uma política sul-americana para a infraestrutura física regional. Isso se evidencia na diversidade de entendimentos sobre o conceito comum a ser adotado sobre infraestrutura e na individualização da busca de fontes de financiamento dos projetos. A IIRSA engendrou uma carteira de projetos que permite a inclusão de projetos individualizados que correspondem a elementos de um projeto estruturante. Isto é, permite aos países incluir seus específicos gargalos históricos de infraestrutura, o que em alguma medida se articulará com a 'vinculação de territórios'.

\section{Mecanismos de financiamento de longo prazo do investimento em infraestrutura regional: a construção de uma política regional de infraestrutura}

O financiamento do investimento em infraestrutura deve dar conta destas suas especificidades, ou melhor, requer-se desembolsos ao longo da maturação (longo prazo) dos projetos. Desde o pós-II Guerra Mundial, a estrutura básica de financiamento deste investimento tem recaído em empresas públicas constituídas de recursos públicos previstos em políticas fiscais, bem como de instituições intergovernamentais. Nos países latino-americanos, o financiamento do investimento até a década de 1980, constituiu uma questão eminentemente de Estado. No entanto, o gasto público com infraestrutura, na região, foi comprometido após um período de expressivo endividamento externo seguido por um período de baixo crescimento com enfraquecimento da posição estatal. Entre 1980-85 os gastos, relação ao PIB, com investimento em infraestrutura representaram 3,71\%, entre 1996 e 2001, esses gastos caíram para 2,24\% do PIB e entre 2002 e 2006 essa proporção chegou a 1,46\% (Rozas, 2010). Além dos gastos públicos, instituições financeiras, como a CAF, desempenharam papel de financiadora de projetos adensados ao objetivo da integração econômica regional. Assim, fontes como CaF, BNDES e o Focem (criado em 2007 pelos países do Mercosul) representariam fontes de crédito em condições mais favoráveis e sem condicionalidades de FMI ou Banco Mundial (Furtado, 2008; Deos et al, 2010).

No âmbito dos estudos específicos sobre o sistema financeiro dos países da região, é possível destacar a análise de Deos, Mendonça e Wegner (2013) pela qual um sistema financeiro completo caracteriza-se por apresentar mecanismos de financiamento de longo prazo, que são essenciais para garantir o financiamento de projetos de investimento em infraestrutura. Boa parte dos países sul-americanos, com base em Jiménez e Manuelito (2010), possui um sistema bancário pouco 'maduro' e as carteiras estão orientadas ao curto prazo. Mendonça (2009) analisa a estrutura dos sistemas financeiros de Argentina, Brasil, Paraguai e Uruguai em busca de evidências de mecanismos de financiamento de longo prazo, bem como da constituição da propriedade das instituições financeiras. Observa a autora que, a despeito de essas economias terem experimentado processos de liberalização e a crise financeira, bem 
Integração e desenvolvimento econômico: estratégias de financiamento do investimento de infraestrutura...

como predomínio de instituições bancárias no mercado de crédito, elas se caracterizam por heterogeneidades em termos de tamanho, profundidade, concentração e tamanho do mercado de capitais. Quanto à presença de instrumentos de financiamento de longo prazo, o Brasil é aquele que detém instrumento de financiamento de longo prazo por meio, especialmente, do Banco Nacional do Desenvolvimento Econômico e Social (BNDES), bem como possui um mercado de capitais.

Bancos e fundos regionais de desenvolvimento podem engendrar esquemas para financiamento de projetos de infraestrutura, ainda que seja necessária a definição de marco jurídico no âmbito da integração regional para estabelecer acesso a fontes de recursos em custos adequados, bem como para garantir o pagamento pelos serviços solicitados (Aportela; Durán, 2011). Além disso, sua atuação pode ser o caminho para dirimir os efeitos da integração em termos de assimetrias entre os países. Afinal, o estabelecimento de um acordo regional, seja uma área de livre comércio seja uma união aduaneira, representa um potencial de crescimento do fluxo comercial e de investimentos entre os países signatários. Além desse efeito, a construção de instrumentos capazes de dirimir as diferenças de desenvolvimento entre os países é indispensável, se se pensar em integração econômica regional como estratégia de longo prazo.

Espera-se ainda a ocorrência da integração financeira, embora "esse processo espontâneo de integração financeira traz problemas mais intensos, já que se dá de forma descontrolada e sem os ajustes necessários"7 (Amado; Silva, 2000, p. 573). As economias relativamente menos desenvolvidas terão maior preferência à liquidez ${ }^{8}$, em função dos seus maiores níveis de incerteza para o investimento. Dessa forma, haverá, dentro deste acordo regional, vazamentos de finance. Os agentes dessa economia comprarão ativos das economias com nível de desenvolvimento relativo maior.

Percebe-se a necessidade de os bancos multilaterais de desenvolvimento (BMD) atuarem de forma arrojada para incorporar graus mais elevados de risco em seus balanços (Costa; Gonzalez; Almeida, 2014). Assim, poderiam ser mais operantes quanto à concessão de financiamentos tradicionais e também poderiam obter novos instrumentos para países que por sua estrutura econômica necessitem de instrumentos financeiros inovadores. Nesse caso, seria possível a implementação de uma série de instrumentos financeiros que amparariam as economias em desenvolvimento em situações reversão abrupta das condições dos mercados internacionais. Interpretam Costa, González e Almeida (2014) que os bancos multilaterais deveriam atuar peremptoriamente em relação aos seus acionistas em desenvolvimento. Devem assumir a função de emprestadores até mesmo no âmbito de suas políticas macroeconômicas em caso de uma diminuição de recursos financeiros.

(7) Os autores se referem de forma mais específica à união monetária, tal como a União Europeia.

(8) A decisão dos agentes não poderá se sustentar em perspectivas futuras, mas em dados do passado, isto é, adotam elementos convencionais. A taxa de juros será o preço que poderá induzir os agentes a abrir mão da liquidez, bem como deverá ser menor do que a eficiência marginal do capital para que os agentes decidam investir. 


\subsection{Articulação entre as fontes de financiamento e a execução dos projetos da carteira IIRSA-Cosiplan}

O fortalecimento patrimonial, e assim a sua capacidade de emprestar, de instituições como Caf e Fonplata deve muito à implementação da IIRSA na medida em que ao coordenarem, no âmbito da IIRSA, suas ações com o BID, alcançaram um fortalecimento de seus indicadores patrimoniais, como ativo e carteira de empréstimos (Padula, 2010). Esse fortalecimento contribui para fortalecer decisões privadas de investimento ao balizar a confiança para investidores privados em relação à viabilidade de projetos (Sagasti, 2006). No entanto, como salienta Honório (2013), mesmo após a incorporação da IIRSA ao Cosiplan, em 2011, a atuação dessas instituições financeiras regionais na integração física sul-americana, está voltada para financiar megaprojetos de infraestrutura que não são orientados para demandas locais e regionais de fato.

\subsubsection{Fundo financeiro para desenvolvimento da bacia do Prata (Fonplata)}

A estrutura acionária do Fonplata, que é o compartilhamento de sua propriedade entre os países acionistas, busca refletir a concepção expressa em sua missão, qual seja, promover o desenvolvimento harmonioso da região da bacia do Prata. Seus recursos próprios somam US\$ 100 milhões dos quais Argentina e Brasil devem contribuir com 33,35\% e os demais países, com $11,1 \%$. Aos acionistas cabe, conforme seu Convênio Constitutivo, decidir sobre as suas estratégias de atuação e sua operação financeira, além da composição do capital. Os países acionistas aportam recursos em situações específicas como aumento de capital e de forma fracionada no tempo, sendo acionistas mutuários - ao mesmo tempo em que aportam recursos podem ser beneficiados por empréstimos.

O Fundo atua nos seguintes itens, caracterizados em seu Convênio como "bens e serviços": (i) empréstimos - para financiar estudos de factibilidade, programas de obras destinados a apoiar a integração entre os países acionistas, incluindo setores de infraestrutura física regional, produção, desenvolvimento ambiental e social; (ii) cooperações técnicas - são oferecidas por meio de serviços de assessoria, os quais devem transferir conhecimentos e experiências para fortalecer a preparação e execução dos projetos de investimento, bem como prestar serviços de gestão dos projetos; (iii) Programa Global de Obras Múltiples e Programa para el Financiamiento Proporcional de Inversiones - destinam-se a financiar obras de um ou mais projetos de investimento, isto é, financia-se parcialmente um dado projeto e em um determinado intervalo de tempo acordado previamente e (iv) linhas de crédito - condicionada a programas de desenvolvimento sob a destinação de recursos para financiar um conjunto de projetos de características similares, constam critérios específicos para elegibilidade.

Os países acionistas, Argentina, Bolívia, Brasil, Paraguai e Uruguai originalmente eram os únicos responsáveis por aportar recursos no Fundo. Em 2010 ${ }^{10}$, os acionistas

(9) Definido em seu Convênio Constitutivo: http://www.fonplata.org/index.php/fonplata/nuestra-historia.

(10) Em 2012, foi anunciado o primeiro presidente executivo do Fonplata. 
Integração e desenvolvimento econômico: estratégias de financiamento do investimento de infraestrutura...

definiram que fontes outras como emissão de bônus, financiamentos com bancos multilaterais podem ser usadas ou a obtenção de recursos junto a agentes privados. Tal mudança de estratégia de aplicações financeiras, logo de geração de funding, é consentânea ao aumento de carteira de empréstimos, de patrimônio líquido e de ativo. Mais detalhadamente, em 2011, a Assembleia de Governadores autorizou o Fundo a comprar títulos da dívida do BID e da CAF, além da tradicional alocação de recursos em títulos do Tesouro Nacional dos EUA ${ }^{11}$.

\subsubsection{Banco de Desenvolvimento da América Latina (CAF)}

A origem da CAF vem da busca pelos países latino-americanos de uma instituição financeira que apoiasse a integração econômica dos países andinos, nos anos 1960, no âmbito da Aladi. Assim, em 1966, a Declaração de Bogotá - tendo em vista o Tratado de Montevidéu - concretizou essa busca e os assinantes foram: Colômbia, Peru, Chile, Equador e Venezuela, em 1967, a Bolívia juntou-se à instituição. De fato, a CAF foi institucionalizada em banco múltiplo e agência de promoção do desenvolvimento econômico e da integração andina a partir do seu convênio constitutivo, assinado em 1968. No ano seguinte, foi estabelecida, por meio do Acordo de Cartagena, a conexão entre essa instituição financeira e a Associação LatinoAmericana de Livre Comércio (ALALC). A ideia de que era necessário um mecanismo alternativo de financiamento da integração para o desenvolvimento econômico - ou para a industrialização - assentava a criação da CAF. Ela representa o primeiro órgão financeiro totalmente latino-americano a buscar fortalecer a integração entre os países andinos, dada a liberalização do comércio promovida entre eles.

Em 2007, foi aprovada em Assembleia da CAF modificação no seu Convênio Constitutivo para a inclusão dos países do Mercosul mais o Panamá como acionistas série "A", além da inclusão de outros países da região nas séries "B" e "C". Os aportes seguiram sendo destinados para infraestrutura (US\$ 1,7 bilhões), desenvolvimento social (US\$1,3 bilhões), bem como passaram a responder a maior demanda por recursos do setor privado. A inclusão do Mercosul entre os países acionistas mutuários da CAF, em 2007, representou sua multilateralização, bem como o aumento do seu capital e da sua capacidade emprestadora.

Os empréstimos concedidos podem ser para financiar projetos, capital e trabalho, atividades de comércio, bem como para elaborar estudos de factibilidade e pré-inversão. A outorga de empréstimos ocorre observando o tipo de risco, isto é, riscos soberanos - sob garantia de governos nacionais - e não soberanos - para setores empresariais e financeiros, sem garantia de governos nacionais. A concessão de empréstimos está atrelada principalmente aos setores de infraestrutura, bem como de integração. Além deles, o financiamento estruturado é usado especificamente para obras de infraestrutura, petróleo e gás natural que tenham

\footnotetext{
(11) Essa mudança trouxe resultados expressivos já no curto prazo. Isto é, se em 2011, as aplicações financeiras mantidas em títulos do tesouro americano (bônus) eram de US\$ 106 milhões, aquelas mantidas em bônus do BID eram de US\$ 13 milhões e mantidas em bônus da CAF, eram de US\$ 9,4 milhões, em 2012, as aplicações em títulos do tesouro americano se reduziram para US\$ 75 milhões, enquanto a alocação de recursos em bônus do BID e da CAF aumentaram para US\$ 17 milhões e 34 milhões, respectivamente.
} 
demanda - ou contratação de governos nacionais. Esse banco é institucionalmente diversificado quanto aos instrumentos que oferece aos acionistas, isto é, mesmo que as operações de empréstimos sejam mais expressivas, também são oferecidas garantais e avais cujo objetivo é desenvolver o mercado de capitais na região e também modalidades mais robustas com financiamento sindicado e estruturado.

\subsubsection{Banco Interamericano de Desenvolvimento (BID)}

Instituição internacional em cujo Convênio Constitutivo, de 1959, é estabelecido seu propósito de "contribuir para a aceleração do processo de desenvolvimento econômico e social dos países-membros da região em vias de desenvolvimento, de forma individual e coletiva". Toda a sua atuação objetiva financiar a promoção de investimento em seus países-membros (Castro, 2011) e a integração regional sempre esteve dentre os objetivos desta instituição, embora nos seus primeiros 30 anos não tenha sido de fato prioritária. Em 1994, na reunião da Assembleia de Governadores sobre a Oitava Reposição do capital do BID, ao reformular sua estratégia, o Banco inclui como uma das prioridades modernizar o Estado e a integração regional de modo que a integração regional deve ser construída de forma a integrar as economias regionais ao mercado mundial. A Nona Reposição de capital ${ }^{12}$, firmada em 2010, promove reforma institucional no Banco de modo a colocá-lo mais próximo dos países membros tendo em vista as suas necessidades, sobretudo, em termos de melhoria do nível de vida da população. Medidas consistentes foram elaboradas para mitigar riscos financeiros, bem como fortalecer o meio ambiente e salvaguardas sociais.

Seus recursos consistem em Capital Ordinário, Fundo de Operações Especiais (FOE), Mecanismo de Financiamento Intermediário (MFI) e no Fundo Não Reembolsável $(\mathrm{GRF})^{13}$. As decisões de outorga de empréstimos e de garantia partem da sua Diretoria Executiva composta de 14 diretores que representam 48 países-membros. Sobre sua estrutura societária, cabem observações relevantes a exemplo da descrição já realizada de CAF e Fonplata.

De seus 48 países membros, apenas 26 são mutuários, os quais detêm 50,02\% do poder de voto na diretoria do BID. Dentre os mutuários, estão todos os 12 países sul-americanos, supondo que desde 1999, 65\% das aprovações de empréstimo são a países como Argentina, Brasil, Chile, Uruguai e Venezuela - chamados de Grupo I, com maior renda per capita - e $35 \%$ para os demais países sul-americanos, que formam o Grupo II, de menor renda per capita. Esses países, bem como os membros mutuários latino-americanos, pertencem também ao Fundo Multilateral de Investimentos (Fumin). Não são mutuários os países desenvolvidos, os quais se beneficiam dos processos de aquisição e contratações, uma vez que apenas empresas

(12) O capital ordinário do banco foi aumentado em US\$ 70 bilhões, bem como foi aumentado o Fundo de Operações Especiais (FSO) em US\$ 479 milhões.

(13) Foi criado em 2007 especificamente como uma fonte de recursos não reembolsáveis para o Haiti. Inicialmente, o Haiti se tornou elegível para receber US\$ 50 milhões por ano de 2007 a 2009. Em 2010, por ocasião da Nona Reposição de Capital do Banco, acordaram-se novas transferências para o Haiti a partir do FOE. 
Integração e desenvolvimento econômico: estratégias de financiamento do investimento de infraestrutura...

dos países membros podem fornecer bens e serviços aos projetos financiados pelo BID. Com base em BID (2015), os países com as maiores participações nas decisões de empréstimo são: EUA (30\%), Argentina (11,2\%), Brasil (11,2\%), México (7,2\%) e Japão (5,0\%). Portanto, há uma discrepância quanto às possibilidades de aprovação de empréstimos. Sua política financeira é notoriamente rígida de modo a manter a sua 'solidez financeira'. Dessa forma, para empréstimos sem garantia soberana há limites e requisitos, como a entidade, seja pública ou privada, execute o projeto em um país mutuário e não seja beneficiário de garantia soberana de amortização de suas obrigações. Operações sem garantia soberana estão limitadas de sorte que não comprometam 20\% do Patrimônio Líquido Total, que em 2014, foi de apenas $7 \%$ ou US\$ 1,7 bilhão.

\subsection{Comparação entre as instituições: indicadores patrimoniais selecionados}

As três instituições individualmente apresentaram relevante aumento de sua carteira de empréstimos. O Banco Regional de Desenvolvimento da América Latina (CAF) engendrou uma transformação em seu capital ao incluir os países do Mercosul na categoria de acionistas "A" de modo que desde 2007, a outorga de empréstimos a esses países é crescente. Fonplata mantém uma atuação bastante mais regionalizada e com certa observância das assimetrias entre seus países membros, tendo em vista que Paraguai, Bolívia e Uruguai recebem maior volume de financiamento e fazem aportes de capital menores. No entanto, projetos de investimento da iniciativa para integração por infraestrutura dos países sul-americanos mantêm participação relativamente menor na carteira de empréstimos de todas as instituições. $\mathrm{O}$ endosso pelo BID e alguma medida pela CAF de financiar as instituições, como exposto na seção anterior, as tornam ainda mais vigilantes quanto a regras de solidez econômica e financeira.

No âmbito da análise regional sobre a cooperação para o financiamento de investimentos, a comparação das instituições financeiras por meio de seus indicadores patrimoniais e operacionais é uma das principais técnicas utilizadas. Ocampo (2006); Sagasti e Prada (2006) elaboraram análises referenciais considerando bancos multilaterais dos países subdesenvolvidos. Deos, Mendonça e Wegner (2013) complementam a comparação de indicadores patrimoniais por meio de indicadores dos sistemas financeiros dos países do Mercosul. Nessa abordagem, mais recentemente, Costa, González e Almeida (2014) tomaram por objetivo a análise do impacto do financiamento de bancos multilaterais sobre a economia brasileira.

A relação prêmio de liquidez da moeda e dos ativos de capital regional não poderia ser manipulada nacionalmente, embora, bancos comerciais possam alterar a liquidez de cada país e, assim, os incentivos a investir, o que induziria a maiores assimetrias. Bancos regionais e/ou fundos de investimento são esquemas importantes de financiamento da integração. De fato, os sistemas financeiros dos países sul-americanos não são suficientes para financiar projetos de longo prazo. Ao se buscar direcionamentos para que os projetos da carteira IIRSA-Cosiplan

sejam executados - considerando que o acesso ao financiamento de longo prazo é a barreira 
nevrálgica - uma exposição e dissertação sobre a alternativa aos sistemas financeiros dos países sul-americanos se constitui uma ferramenta pertinente.

Entre o banco multilateral regional, o BID, e as instituições financeiras regionais, CAF e Fonplata existem significativas diferenças, sobretudo, em termos de capital, patrimônio, indicadores operacionais, dentre outros (Tabela 6). A qualificação de risco é relativamente desfavorável à CAF (AA-) e ao Fonplata (BBB-), banco e fundo genuinamente latinoamericanos. A magnitude de capital de ambos é desproporcional em relação ao BID. A composição de capital é peculiar na CAF - a relação capital pago e subscrito é de 43\%, contra menos de $10 \%$ do BID e 30\% do Fonplata (Tabela 6). Essa discrepância pode ser um reflexo da estrutura acionária majoritária de países com menor nível de desenvolvimento econômico. É necessário que a CAF atue com um volume maior de recursos disponíveis, isto é, o capital pago.

Tabela 6

América do Sul: estrutura patrimonial e operacional de instituições financeiras em 2014 (Em US\$ milhões)

\begin{tabular}{|c|c|c|c|}
\hline Indicadores & BID & CAF & FONPLATA \\
\hline Ativos & 106.299 & 30.495 & 573 \\
\hline Capital subscrito & 144.258 & 4.250 & 1.639 \\
\hline Capital exigível & 138.901 & 21.731 & 0,484 \\
\hline Patrimônio ${ }^{1}$ & 162.505 & 8.763 & 0,495 \\
\hline Carteira Empréstimos a cobrar & 74.585 & & 0,367 \\
\hline Aprovação de empréstimos & 12.652 & 11.724 & 0,227 \\
\hline Número de projetos aprovados & 167 & 164 & 10 \\
\hline Gastos administrativos & 19 & 70 & 4 \\
\hline Número de países membros & 48 & 18 & 4 \\
\hline Número de países mutuários & 26 & 18 & 4 \\
\hline Qualificação de crédito (média) & AAA & AA- & BBB- \\
\hline Capital Pago/Capital subscrito (\%) & 6 & 51 & 30 \\
\hline $\begin{array}{l}\text { Gastos administrativos/Aprovação } \\
\text { de empréstimos }(\%)\end{array}$ & 0,15 & 1 & 2 \\
\hline $\begin{array}{l}\text { Coeficiente de capital ponderado } \\
\text { em função do risco }\end{array}$ & 3,4 & 2,3 & 6,4 \\
\hline Coeficiente de alavancagem ${ }^{3}$ & 0,55 & 2,4 & 0,02 \\
\hline Patrimônio/Ativos (\%) & 1,5 & 0,29 & 98,2 \\
\hline Valor médio dos projetos ${ }^{4}$ & 75,8 & 71,49 & 22,7 \\
\hline \multicolumn{4}{|c|}{$\begin{array}{l}{ }^{2} \text { Relação entre os empréstimos pendentes de reembolso e o patrimônio. } \\
{ }^{3} \text { Relação entre os empréstimos pendentes de reembolso e o patrimônio + o capital exigível (empréstimos } \\
\text { pendentes/capital total). }\end{array}$} \\
\hline
\end{tabular}


Integração e desenvolvimento econômico: estratégias de financiamento do investimento de infraestrutura...

Operacionalmente, o BID aprovou US\$ 13 bilhões em empréstimos, menos de US\$ 1 bilhão do total aprovado pela CAF, em 2014 (Tabela 6). De fato, a atuação do Fonplata foi bastante restrita, em 2014, não representando nem mesmo $1 \%$ das aprovações pela CAF. Vale ressaltar que enquanto o BID possui uma atuação global - com 48 países membros e 26 mutuários - CAF possui apenas 18 países acionistas, também mutuários. Assim, “operações de curta maturação e com uma carteira de financiamento relativamente equilibrada em termos de empréstimos com risco soberano e não soberano, que lhe permite retorno mais rápido sobre o capital investido" Costa, González e Almeida (2014, p. 20).

O BID apresentou, em 2014, a maior relação entre gastos administrativos e empréstimos aprovados (15\%), enquanto CAF apresentou a menor relação (1\%). O banco latino-americano apresentou um gasto menor no preparo de suas operações de financiamento. O Fonplata, embora mantenha nível mais modesto de operações, apresentou um gasto administrativo maior ao da CAF (2\%). Costa, González e Almeida (2014) explicam que a CAF financia, sobretudo, projetos de investimentos de setores da infraestrutura viária e urbana cuja complexidade é menor. BID e CAF, em 2014, juntos aprovaram 331 projetos a seus acionistas, mantendo o mesmo patamar de 2012, como mostrado pelos autores citados.

Em termos de solidez e suficiência financeiras, foram utilizados os indicadores de coeficiente de alavancagem e de capital ponderado em função do risco (Tabela 6). Ambos possibilitam avaliar o grau de alavancagem das instituições ao considerar a relação entre a carteira de empréstimos pendentes de reembolso, ou seja, aqueles recursos que foram desembolsados, mas ainda não repagados, e o capital (Costa; González; Almeida, 2014). Todas as instituições apresentaram alavancagem bastante inferior ao estipulado nos acordos de Basiléia III $^{14}$. Por outro lado, a relação entre os empréstimos e capital total da CAF expõe um grau de alavancagem elevado, o que estaria abaixo do nível considerado conservador a ser praticado por bancos multilaterais de desenvolvimento.

Mesmo que mantenham em seus convênios constitutivos o objetivo de financiar projetos que promovam desenvolvimento econômico e integração regional, as instituições financeiras seguem uma lógica de manter políticas operacionais atinentes a rígidos critérios de sustentabilidade financeira. Nesse sentido, o BID reforçou, na última década, um modelo de gestão de resultado para assegurar a sua solidez de ativos ${ }^{15}$. Fonplata ao receber aporte de capital de instituições multilaterais, reforçou suas regras de solidez financeira.

A infraestrutura de integração é uma das áreas que menos recebeu recursos (em termos de aprovação de empréstimos em 2014) (Tabela 7). O total de empréstimos aprovados pela

(14) Os Acordos de Basileia III preveem como sendo de $8 \%$ o requisito mínimo de capital para empréstimos do setor bancário privado, o que equivale a uma relação entre empréstimos e capital de 12,5 (conceito estrito).

(15) Mais especificamente o novo modelo: "confirmou que a sustentabilidade financeira e as funções de supervisão da organização foram reforçadas, destacando especificamente o fato de que o IMM estabelece um vínculo transparente entre as receitas do $\mathrm{CO}$ e o empenho de recursos no horizonte de longo prazo, estabelecendo uma disciplina maior no uso de recursos do Banco e, ao mesmo tempo, permitindo que ele continue a atender às demandas de recursos da região" (BID, 2015, p. 18). 
CAF em 2014 chegou a US\$ 11 bilhões, enquanto que em relação aos projetos de infraestrutura física regional, ao longo dos últimos anos sua participação é de US\$ 7 bilhões.

Tabela 7

América do Sul: Aprovações de empréstimos por área estratégica em 2014 (US\$ milhões)

\begin{tabular}{l|c|c|c}
\hline Áreas & BID $^{1}$ & CAF & Fonplata \\
\hline Sistemas financeiros & 2.547 & 5.293 & -- \\
\hline Infraestrutura econômica & 4.879 & 2.646 & 97,6 \\
\hline Desenvolvimento social e ambiental & 2.505 & 1.762 & 31,8 \\
\hline Setor produtivo & 756 & 1.012 & -- \\
\hline Reformas estruturais & 2.227 & 850 & - \\
\hline Infraestrutura de integração & 28 & 121 & 96,5 \\
\hline Fundos de cooperação & - & 40 & -- \\
\hline Total & 8.754 & 11.724 & 227 \\
\hline
\end{tabular}

${ }^{1}$ O BID usa denominação diferente das áreas de aprovação de empréstimos. Nesta tabela, em infraestrutura econômica, se está considerando transportes, água e saneamento, energia, desenvolvimento urbano e habitação. Em reformas estruturais, reforma/modernização do Estado, setor produtivo, agricultura e desenvolvimento rural, ciência e tecnologia e pequenas e médias empresas. Infraestrutura da integração, apenas integração econômica. Fonte: Relatórios anuais e financeiros auditados (2014).

\section{Considerações finais}

Investimentos de longo prazo de maturação, tais como infraestrutura, serão executados na medida em que seus tomadores de decisão encontrarem mecanismos efetivos para financiar todas as etapas do projeto. Esses mecanismos, espera-se, deverão cumprir as vezes de reduzir o grau de incerteza ao qual os tomadores de decisão estão envoltos. Bancos têm preferência pela liquidez com base em suas expectativas em relação a incertezas da passagem do tempo para formar seus ativos e passivos. Países em desenvolvimento contam basicamente com a arrecadação tributária para gerar recursos financeiros para financiar investimentos, sendo primordial a atuação de fontes alternativas, como bancos de desenvolvimento regionais/multilaterais.

O financiamento público via tesouros nacionais é o principal mecanismo de financiamento dos projetos em execução. Setor privado e fontes outras como as supracitadas não têm completado as necessidades de financiamento de longo prazo da IIRSA-Cosiplan. Mesmo o Cosiplan buscando uma aderência mais orgânica da construção da infraestrutura regional com os objetivos da Unasul relacionados à promoção da integração econômica regional com mudança estrutural, os avanços quanto aos mecanismos financeiros para executar tais investimentos não têm se mostrado mais circunstanciais quanto aos objetivos da Unasul e muito mais atentos a manter a eficiência financeira dessas instituições. A política de fortalecer os indicadores de solidez financeira dessas instituições pode ser um obstáculo para as mudanças que as tornariam mais competitivas, tais como novas abordagens de financiamento e capacidade de mobilizar recursos financeiros na medida e nas condições de seus países acionistas. 
Integração e desenvolvimento econômico: estratégias de financiamento do investimento de infraestrutura...

Até o momento da elaboração deste artigo tem-se alguns aspectos delineados a respeito do financiamento da infraestrutura da integração sul-americana: (i) os sistemas financeiros dos países da região são pouco integrados e não contam com mecanismos de financiamento de longo prazo, além de guardarem alguma heterogeneidade entre si; (ii) a maior parte da carteira de projetos IIRSA-Cosiplan está estruturada em torno do financiamento público via Tesouro Nacional; (iii) os bancos regionais e multilaterais de desenvolvimento exercem atuação marginal, tendo em vista que sua outorga de empréstimos depende das decisões dos governos nacionais sobre quais projetos solicitarão financiamento e, por fim, (iv) é possível destacar algum avanço na modalidade de financiamento privado via agentes privados/corporativos. Instituições como CAF e Fonplata vêm se revestindo de política de solidez financeira - sob a justificativa de acessar os mercados internacionais de capitais - que pode limitar ainda mais sua atuação emprestaticia da carteira IIRSA-Cosiplan. As parcerias público-privadas ou o financiamento totalmente privado acabam por se mostrar como as únicas 'saídas'.

Assim, não está clara a vinculação dos empréstimos outorgados com projetos de integração. E como consequência do anterior, os projetos financiados são comumente destinados a municípios, estados ou empresas - bem como instituições bancárias. Não há indicadores do impacto de obras, programas e projetos financiados sobre o processo de integração regional, até mesmo porque o saldo de projetos aprovados e concluídos é negativo, como se argumentou na primeira seção deste artigo. Entre os países sul-americanos ainda não existe acordo em termos do impacto fiscal dessa buscada conexão física entre eles sobre o aumento do comércio internacional, ou melhor, a criação de um fundo comum cujos recursos financeiros - que seguiriam financiando o processo - viessem de tarifas alfandegárias não é estabelecido.

\section{Referências bibliográficas}

AMADO, A. M.; SILVA, L. A. S. Considerações sobre as perspectivas nacionais e regionais do processo de integração monetário-financeira do Mercosul. Estudos Econômicos, São Paulo, v. 30, n.4, p. 571-596, 2000.

APORTELA, Fernando; DURÁN, Roberto. La infraestructura en el desarrollo integral de América Latina: diagnóstico estratégico y propuestas para una agenda prioritaria. Financiamiento: retos y oportunidades. Bogotá: CAF, 2011. 106p.

BUHR, Walter. What is infrastructure? University of Siegen, 2003. 32p. (Texto de Discussão, n. 107).

CARNEIRO, Ricardo. Notas sobre a integração sul-americana. In: SEMINÁRIO SOBRE INTEGRAÇÃO DA AMÉRICA DO SUL, realizado pela Funag, em 23 de julho de 2009. Rio de Janeiro: Funag, 2009.

CASTRO, Augusto César Batista de. Os bancos de desenvolvimento e a integração da América do Sul: bases para uma política de cooperação. Brasília: Fundação Alexandre de Gusmão, 2011. 176p. 
CECEÑA, A. E. et al. Territorialidad de la dominación: integración de la infraestructura Regional Sudamericana (IIRSA). Buenos Aires: Observatorio Latinoamericano de Geopolítica, 2007. 60p

CECEÑA, Ana Esther. Caminos y agentes del saqueo en America Latina. 23 out. 2009. Disponível em: http://alainet.org/active/33914.

CINTRA, Marco Antônio Macedo; FARHI, Maryse. A arquitetura do sistema financeiro internacional contemporâneo. Revista de Economia Política (Impresso), v. 29, p. 274-294, 2009.

CORRÊA, Vanessa Petrelli. A participação privada nos investimentos de infra-estrutura - a questão do financiamento. In: ENCONTRO NACIONAL DE ECONOMIA POLÍTICA DA SEP, 3, 1998, Niterói. Anais... Niterói: Sociedade Brasileira de Economia Política, 1998. v. II. p. $672-684$.

COSTA, Carlos Eduardo Lampert; GONZÁLEZ, Manuel José Forero; ALMEIDA, Nathália Filgueiras de. As relações econômicas do Brasil com os principais bancos multilaterais de desenvolvimento. Boletim de Economia e Política Internacional, v. 16, p. 57-74, 2014.

COUTO, Leandro Freitas. O horizonte regional do Brasil e a construção da América do Sul. Revista Brasileira de Política Internacional, v. 50, n. 1, p. 159-176, 2007.

DEOS, Simone; MENDONÇA, Ana Rosa Ribeiro; WEGNER, Rubia. Cooperação financeira no Mercosul e o financiamento do investimento. Nova Economia (UFMG. Impresso), v. 23, p. 155-184, 2013.

DEOS, Simone; MENDONÇA, Ana Rosa Ribeiro; WEGNER, Rubia. Financiamento do investimento em um contexto de cooperação financeira: avaliação dos avanços no âmbito do mercosul. In: KUPFER, David; LAPLANE, Mariano F.; HIRATUKA, Célio. (Org.). Perspectivas do investimento no Brasil: temas transversais. 1. ed. Rio de Janeiro: Synergia, 2010, v. 4, p. 251-293.

DIEWERT, W. E. The measurement of the economic benefits of infrastructure services. Lecture notes in economics and Mathematical Systems, v. 278, 1986.

FURTADO, Fabiana. Integração financeira da América do Sul. Banco do Sul: mais do mesmo ou oportunidade histórica? Oikos, v. 9, n. 7, p. 173-190, 2008.

HONÓRIO, Karen dos Santos. O significado da iniciativa para a integração da infraestrutura regional sul-americana (IIRSA) no regionalismo sul-americano (2000-2012): um estudo sobre a iniciativa e a participação do Brasil. Dissertação (Mestrado)-Programa de Pós-Graduação em Relações Internacionais do San Tiago Dantas (Unesp-Unicamp-PUC-SP), São Paulo, 2013. $133 \mathrm{p}$.

JIMÉNEZ, Luis Felipe; MANUELITO, Sandra y. América Latina: sistemas financeiros y financiamento de la inversión - diagnósticos y propuestos. Revista de la Cepal, Santiago, n. 109, 2010. 
Integração e desenvolvimento econômico: estratégias de financiamento do investimento de infraestrutura...

LAKSHMANAN, T. R. Infrastructure and economic transformation. In: ANDERSSON, A. E. et al. (Ed.) Advances in spatial theory and dinamics. Amsterdan: Elsevier, 1989. p. 241-261.

MENDONÇA, Ana Rosa Ribeiro de. Sistemas financeiros do Mercosul: estrutura, financiamento de longo prazo e interpenetração de capitais. Campinas: IE/Unicamp, 2009. 54p. (Texto para Discussão, n. 166).

OCAMPO, J. A. La cooperación financiera regional: experiencias y desafios. In: OCAMPO, J. A. (Org.). Cooperación financiera regional. Santiago: Cepal, 2006. p. 13-56.

PADULA, Raphael. Da IIRSA ao Cosiplan da Unasul: a integração de infraestrutura na América do Sul nos anos 2000 e suas perspectivas de mudança. In: DESIDERÁ NETO, Walter Antonio. (Org.). O Brasil e novas dimensões da integração regional. 1. ed. Brasília: Ipea, 2014. p. 291-352.

PADULA, Raphael. Integração regional de infra-estrutura e comércio na América do Sul nos anos 2000: uma análise político-estratégica. Tese (Doutorado)-COPPE/UFRJ, 2010. 311p.

PRADA, Fernando. World Bank, Inter-American development bank and Subregional development banks in Latin America: dynamics of a system of multilateral development banks. Tokyo: Asian Development Bank Institute, 2012. 35p. (ADBI Working Paper, n. 380).

ROZAS, Patricio. América Latina: problemas y desafíos del financiamiento de la infraestructura. Revista Cepal, Santiago do Chile, n. 101, p. 59-83, ago. 2010.

SAGASTI, Francisco. La banca multilateral de desarrollo en América Latina. Santiago de Chile, Chile: Unidad de Estudios Especiales, Cepal, 2002.

SAGASTI, Francisco; PRADA, Fernando. Bancos regionales de desarrollo: una perspectiva comparativa. In: OCAMPO, J. A. (Org.). Cooperación financiera regional. Santiago: Cepal, 2006. p. 91.

SARTI, F.; HIRATUKA, C. Internacionalização de empresas brasileiras no período recente. Relatório Final Projeto de Pesquisa IPEA/IE-Unicamp, maio 2010. 46p.

SIMAS, Caio de Almeida. A construção de infraestrutura física e os desafios para a integração sul-americana: uma análise espacial da IIRSA e da Unasul. Tese (Doutoramento)-PEPI/UFRJ, 2012. 142p.

TEIXEIRA, R. A.; DESIDERÁ, Walter. A recuperação do desenvolvimentismo no regionalismo latino-americano. Brasília: Ipea, 2012. p. 1-37. (Texto para Discussão, v. 1790).

TOMASSIAN, Georgina Cipoletta. Financiamento de la infraestructura para la integración regional: alternativas para América del Sur. Cepal, 2015. 82p. (Serie Financiamiento para el Desarrollo, n. 259). 
Rubia Cristina Wegner

\section{Anexo}

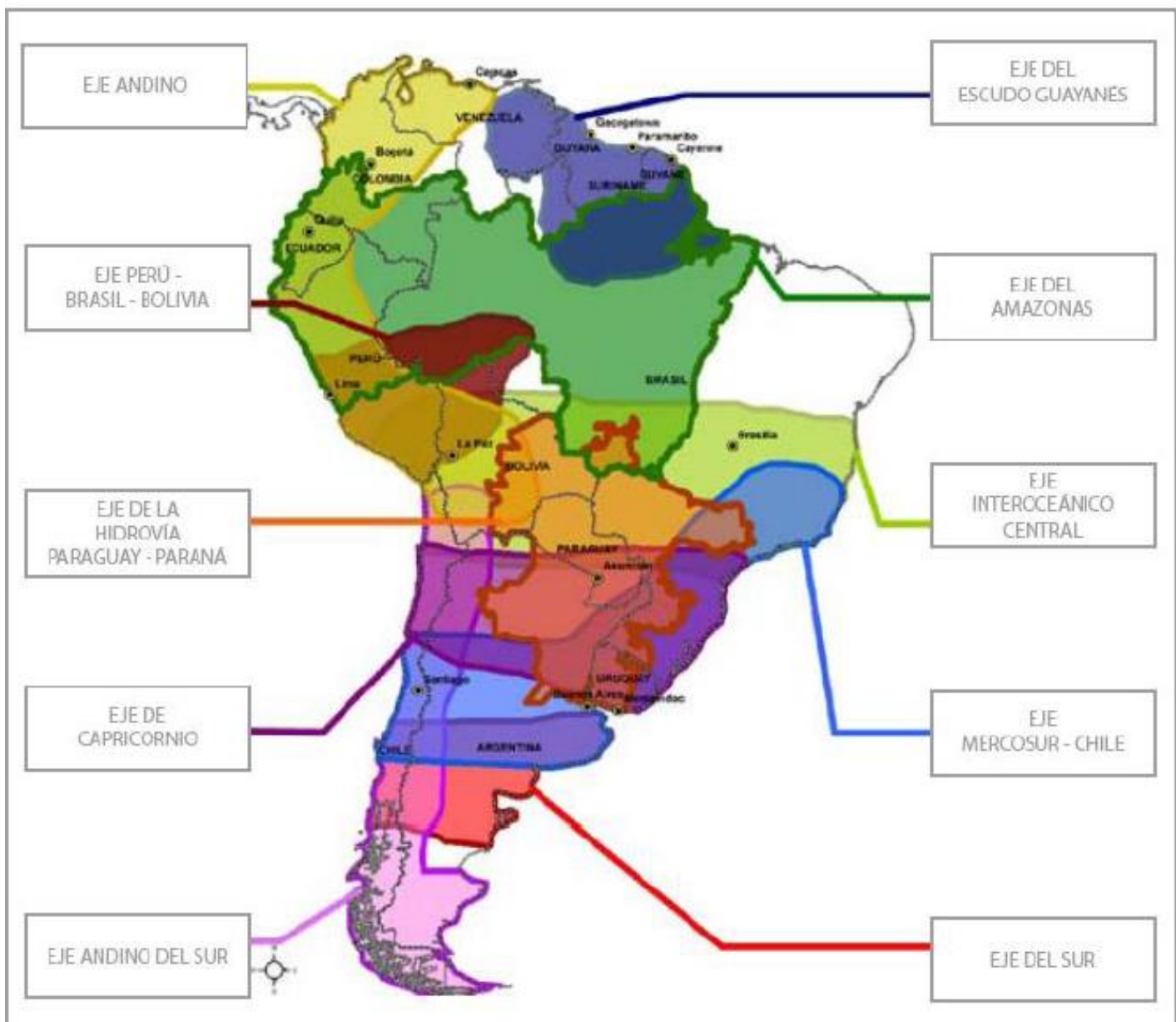

Fonte: Simas (2012). 